\title{
WILEY-VCH
}

DOI: $10.1002 /$ ((please add manuscript number))

Article type: Full Paper

\section{Generation and Characteristics of IV-VI transition Metal Nitride and Carbide Nanoparticles using a Reactive Mesoporous Carbon Nitride}

Nawal S. Alhajri, ${ }^{a}$ Dalaver H. Anjum, ${ }^{b}$ Mohamed N. Hedhili, ${ }^{b}$ and Kazuhiro Takanabe ${ }^{* a}$

N. S. Alhajri, Prof. K. Takanabe

King Abdullah University of Science and Technology (KAUST), KAUST Catalysis Center (KCC) and Physical Science and Engineering Division (PSE), Thuwal, 23955-6900 Saudi Arabia.

E-mail: kazuhiro.takanabe@kaust.edu.sa

Dr. D. H. Anjum, Dr. M. N. Hedhili

King Abdullah University of Science and Technology (KAUST), Advanced Nanofabrication, Imaging and Characterization Core Lab, Thuwal, 23955-6900 Saudi Arabia.

Abstract:

Interstitial nitrides and carbides of early transition metals in groups IV-VI exhibit platinum-like electronic structures, which make them promising candidates to replace noble metals in various catalytic reactions. Herein, we present the preparation and characterization of nano-sized transition metal nitries and carbides of groups IV-VI (Ti, V, Nb, Ta, Cr, Mo, and $\mathrm{W}$ ) using mesoporous graphitic carbon nitride $\left(\mathrm{mpg}-\mathrm{C}_{3} \mathrm{~N}_{4}\right)$, which not only provides confined spaces for restricting primary particle size but also acts as a chemical source of nitrogen and carbon. We studied the reactivity of the metals with the template under $\mathrm{N}_{2}$ flow at $1023 \mathrm{~K}$ while keeping the weight ratio of metal to template constant at unity. The produced nanoparticles were characterized by powder X-ray diffraction, CHN elemental analysis, nitrogen sorption, X-ray photoelectron spectroscopy, and transmission electron microscopy. The results show that $\mathrm{Ti}, \mathrm{V}, \mathrm{Nb}$, Ta, and $\mathrm{Cr}$ form nitride phases with face centered cubic structure, whereas Mo and W forme carbides with hexagonal structures. The tendency to form nitride or carbide obeys the free formation energy of the transition metal nitrides and carbides. This method offers the potential to prepare the desired size, shape and phase of transition 


\section{WILEY-VCH}

metal nitrides and carbides that are suitable for a specific reaction, which is the chief objective of materials chemistry.

\section{Introduction}

Transition metal nitrides and carbides of groups (IV-VI) are a group of compounds possessing electric, magnetic and catalytic characteristics that make them potential substitutes for noble metals in various material science and heterogeneous catalysis applications. ${ }^{[1-4]}$ The electronic properties of metal nitrides and carbides are well known to determine their reactivity and stability. ${ }^{[5,6]}$ The modification occurring in the metal d-band upon nitride and carbide formation is responsible for their excellent catalytic properties. ${ }^{[2]}$ Studies confirmed that hybridization between d-orbital of the metal and p-orbital of non-metal causes an expansion of metal lattice which resulted in a contraction of the metal d-band.

Consequentially, this contraction leads to a higher density of states (DOS) near the Fermi level approaching the $\mathrm{d}-$ band of $\mathrm{Pt}^{[3,7-9]}$ Thus, transition metal nitrides and carbides exhibit catalytic properties similar to those of the noble metals in various reactions, including hydrogenolysis, hydrogenation, dehydrogenation, isomerization, ${ }^{[5]}$ hydrodesulfurization (HDS), hydrodenitrogenation (HDN) ${ }^{[11]}$ ammonia synthesis, ${ }^{[12,13]}$ ammonia decomposition, ${ }^{[14]}$ and electrochemical reactions. ${ }^{[8,9,15]}$ The catalytic activities of interstitial nitrides and carbides depend on their surface composition and on conditions that are strongly related to their synthesis methods. ${ }^{[9,16]}$

The traditional approaches to synthesize transition metal nitrides and carbides limit their use in catalytic application because they suffer from many drawbacks such as large particle size, high energy consumption, poor crystallinity, and incomplete reactions, which result in $\mathrm{O}, \mathrm{C}$ and $\mathrm{N}$ contaminations. ${ }^{[17]}$ Considerable attention has been focused on developing effective methods that can directly enable both changing the end result from nitrides to carbides and controlling the size and shape of the produced nanoparticles. One 


\section{WILEY-VCH}

possible approach reported in the literature is the urea-glass route, a sol-gel process reported by Giordano et al. ${ }^{[1,18,19]}$ This study presents a unique method to change the obtained compounds from nitrides to carbides, i.e., from $\mathrm{Mo}_{2} \mathrm{~N}$ to $\mathrm{Mo}_{2} \mathrm{C}$ and $\mathrm{W}_{2} \mathrm{~N}$ to $\mathrm{WC}$, respectively, simply by changing the ratio of urea to metal precursor. A low urea-to-metal ratio tends to produce nitride, whereas carbide is obtained at higher urea-to-metal ratios. ${ }^{[18-20]}$ This method was applied for other transition metals to obtain $\mathrm{TiN}, \mathrm{VN}, \mathrm{NbN}, \mathrm{GaN}$, and $\mathrm{TiC}(\mathrm{N})$. Research led by Antonietti demonstrated the use of mesoporous graphite mpg- $\mathrm{C}_{3} \mathrm{~N}_{4}{ }^{[21-24]}$ to synthesize metal nitrides nanoparticles such as $\mathrm{TiN}^{[15]} \mathrm{VN},{ }^{[25]} \mathrm{GaN},{ }^{[25]} \mathrm{Ta}_{3} \mathrm{~N}_{5}{ }^{[22,26]}$ and ternary Al-Ga-N and Ti-V-N ${ }^{[27]}$ nanoparticles. Our group reported a unique synthetic approach to synthesize molybdenum and tungsten carbide nanoparticles with sizes of 3 and $5 \mathrm{~nm}$, respectively, using mpg- $\mathrm{C}_{3} \mathrm{~N}_{4}$ as a reactive template, and the produced nanoparticles show high current for hydrogen evolution reaction in acidic media. ${ }^{[28,29]}$ Additionally, we reported the synthesis of different phases of tantalum carbide, carbonitride, and nitride nanoparticles with cubic structures directly through the reaction of a metal precursor with the mpg- $\mathrm{C}_{3} \mathrm{~N}_{4}$ template. ${ }^{[30]}$ Using the mpg- $\mathrm{C}_{3} \mathrm{~N}_{4}$ template approach to synthesize transition metal nitrides and carbides nanoparticles is a unique method because the template both confines the particle growth and provides carbon and nitrogen elements. The mpg- $\mathrm{C}_{3} \mathrm{~N}_{4}$ completely decomposes into reactive $\mathrm{C}$ and $\mathrm{N}$ fragments at approximately $950 \mathrm{~K}$, even under an inert atmosphere (e.g., $\mathrm{N}_{2}$ or Ar) ${ }^{[31]}$ whereas other conventional carbon sources require the air to be gasified. ${ }^{[22]}$ During the synthesis, there is no need for isolation or purification steps due to the complete thermal decomposition of $\mathrm{C}_{3} \mathrm{~N}_{4}$. Additionally, this approach provides control over the size and shape of the resultant nanoparticles as they reflect the size and shape of the original silica template used to generate the mpg- $\mathrm{C}_{3} \mathrm{~N}_{4}$. Applying different silica templates in the $\mathrm{C}_{3} \mathrm{~N}_{4}$ preparation results in various pore shapes and sizes, which consequently produce different morphologies in the transition metal nitrides and carbides. ${ }^{[22,31,32]}$ Studies show that the size is associated with the concentration of the metal precursor solution used in the synthesis. Concentrated 


\section{WILEY-VCH}

solutions yield larger particle sizes, whereas smaller particle size are obtained from dilute solutions. ${ }^{[21]}$

In this paper, we present a general synthetic procedure for preparing a whole class of early transition metal nitride and carbide nanoparticles of groups IV, V, and VI by applying the $\mathrm{C}_{3} \mathrm{~N}_{4}$ template approach. In addition, we studied the reactivity of the transition metal precursors with mpg- $\mathrm{C}_{3} \mathrm{~N}_{4}$, which acts as a chemical source of carbon or nitrogen for the formation of nitride or carbide nanoparticles, respectively. By conducting experiments on a series of transition metals, we identified clear tendencies to form either nitride or carbide under similar conditions, reflecting the identity of parent metal. Our study proved the effectiveness of such a method to produce different phases of interstitial nitride and carbide nanoparticles that could be applied accordingly in a wide range of applications in chemistry and materials science.

\section{Results and Discussion}

The mpg- $\mathrm{C}_{3} \mathrm{~N}_{4}$ template used was reported in our previous report. ${ }^{[28,29]}$ Briefly, the BET surface area is $162 \mathrm{~m}^{2} \mathrm{~g}^{-1}$, and the pore volume and average pore size are $0.35 \mathrm{~cm}^{3} \mathrm{~g}^{-1}$ and $6 \mathrm{~nm}$, respectively. The decomposition products were hydrogen cyanide, nitrogen and cyanogen, respectively, detected by mass spectroscopy, together with $\mathrm{C}_{3} \mathrm{~N}_{\mathrm{x}}$ residue (likely melamine fragments) at the outlet of the reactor.

Different transition metal nitride and carbide nanoparticle phases were produced via the reaction of the metal precursors with the $m p g-C_{3} N_{4}$ template that both confines the particle growth and provides carbon and nitrogen. The reaction was conducted at a constant temperature of $1023 \mathrm{~K}$ under nitrogen flow while keeping the weight ratio of $\mathrm{C}_{3} \mathrm{~N}_{4}$ to the metal precursor constant at 1:1. Our previous study demonstrated that different metal-to$\mathrm{C}_{3} \mathrm{~N}_{4}$-precursor ratios cause different chemical potentials for $\mathrm{C} / \mathrm{N}$ in the reactor, thus leading to additional reactions that form nitride and carbide. In this study, we maintain conditions 


\section{WILEY-VCH}

similar to this ratio, so that the tendency to form one or the other type of compound reflected the nature of the metal used.

The expected reaction pathway may include the following steps. First, a metal orthoester was likely formed by dissolving the metal chloride in alcohol followed by removing $\mathrm{HCl}$. Then, an incipient wetness method was used to impregnate the solution into the mpg- $\mathrm{C}_{3} \mathrm{~N}_{4}$ template at room temperature, where there are no reactions to form $\mathrm{M}-\mathrm{C}$ or $\mathrm{M}-$ $\mathrm{N}$. When the mixture was heated to $960 \mathrm{~K}$, the reactive template $\mathrm{C}_{3} \mathrm{~N}_{4}$ decomposed into active carbon and nitrogen species. ${ }^{[28,29]}$ These highly active species can reduce the metal centers and produce corresponding nitrides or carbides via carbothermal reduction followed by either nitridation or carburising process. In general, carbon or nitrogen active species compete to bind the transition metal atoms. As a result, either transition metal nitrides or carbides are formed based on the reactivity of the transition metals towards nitrogen and carbon fragments.

Early transition group (IV-VI) metal nitrides and carbides exhibit close-packed structures where carbon or nitrogen occupies specific interstitial sites on the metal lattice. ${ }^{[1-}$ ${ }^{3,7,33]}$ Studies show that, interstitial compounds can be formed when the ratio of the radius of the interstitial atom to the radius of the host metal atom is less than $0.59 .^{[2,3,33,34]}$ Among the products obtained with various metals, there were two distinctive groups of crystal structures. $\mathrm{Ti}, \mathrm{V}, \mathrm{Nb}$, Ta and $\mathrm{Cr}$ formed face centered cube phases with the Fm-3m (225) space group as shown in XRD patterns with main diffraction peaks of (111), (200), (220), and (311) (Fig. 1). The d-spacings well reflect ionic radii of the metals, which were in the order, $\mathrm{Cr}$ (III) $<$ V(III) $<\mathrm{Ti}(\mathrm{III})<\mathrm{Nb}(\mathrm{III}) \sim \mathrm{Ta}(\mathrm{III})$ as listed in Table 1 . These phases were all assignable to nitride phase as PDF references listed in Table 1. For Cr sample, the sharp peak indicates the formation of crystalline $\mathrm{CrN}$ ( $25 \mathrm{~nm}$ from Scherrer equation). For Ta sample, XRD pattern assignable to $\mathrm{Ta}_{2} \mathrm{O}_{5}$ was also observed, which was possibly formed upon the exposure to the ambient after the synthesis at room temperature. The very weak peaks assignable to TaN in cubic structure was evidenced, where further details were discussed in our previous 


\section{WILEY-VCH}

publication. ${ }^{[30]}$ In the case of Mo and $\mathrm{W}$, hexagonal structure was obtained, ascribable to $\mathrm{W}_{2} \mathrm{C}$ or $\mathrm{Mo}_{2} \mathrm{C}$ (PDF references are listed in Table 1), as reported in our previous publication. ${ }^{28,29]}$ In addition, broad peaks ascribable to $\mathrm{MoC}(\mathrm{N})$ and $\mathrm{WC}(\mathrm{N})$ phase was also observed, with small shoulder peak of metallic phase for $\mathrm{W}$, which confirms that the reductive process happens during this synthesis in the case of W. ${ }^{[28,29]}$

The electronic factor was explained using the Engel-Brewer theory, which states that the resultant structure depends on the number of sp electrons. The metallic Mo possesses a bcc structure, whereas $\mathrm{Mo}_{2} \mathrm{C}$ and $\mathrm{Mo}_{2} \mathrm{~N}$ are hcp and fcc, respectively. ${ }^{[2]}$ The structure changes from bcc to hep to fcc with increasing amounts of sp electrons. ${ }^{[2]}$ The incomplete filling of the d-band for transition metals of group IV and V drives them to receive a high proportion of $\mathrm{sp}$ electrons and accordingly produce an fcc structure. However, transition metals in group VI possess an hcp structure with metal-rich stoichiometry because of the increased d-band filling. ${ }^{[2,7,35]}$ Additionally, the formation of high metal stoichiometry was in accordance with an attempt to avoid filling of antibonding levels in the metal bands. ${ }^{[5]}$

XPS spectra of the obtained samples for core levels of N 1s, C 1s, O 1s, and metal (Ti 2p, V 2p, Nb 3d, Ta 4f, Cr 2p, Mo 3d, W 4f) are shown in Fig. 2. First, it was noticeable that strong signals of the $\mathrm{O} 1 \mathrm{~s}$ peaks at $530-531 \mathrm{eV}$ were obtained, which are assigned to metal oxides in all the samples. ${ }^{[36-44]}$ Due to the passivation step at the end of the synthetic procedure in addition to the exposure of the sample to ambient air, an oxide layer was formed on the surface even though the samples were completely cooled to room temperature. ${ }^{[28,29]}$ On the other hand, $\mathrm{N}$ 1s at $396-397 \mathrm{eV}$, which is assigned to metal nitride phase, was observed for $\mathrm{Ti}(\mathrm{TiN}),{ }^{[45,46]} \mathrm{Nb}(\mathrm{NbN}),{ }^{[47]} \mathrm{Ta}(\mathrm{TaN}),{ }^{[48,49]} \mathrm{Mo}\left(\mathrm{MoN}(\mathrm{C}), \mathrm{W}\left(\mathrm{W}_{2} \mathrm{~N}(\mathrm{C})\right),{ }^{[50]}\right.$ and most clearly $\mathrm{Cr}(\mathrm{CrN}) .{ }^{[51,52]}$ As for $\mathrm{V}$, nitride peak was not detectable although XRD pattern indicates the formation of VN. This can be due to the surface oxidation of the sample. The peaks of $\mathrm{N} \mathrm{1s}$ at 398-402 eV were assigned to carbon nitride residue (nitrogen bonded to sp and $\mathrm{sp}^{2}$ carbon), coinciding the broad peaks for $\mathrm{C} 1 \mathrm{~s}$ at $285-287 \mathrm{eV} \cdot{ }^{[30,53,54]}$ The $\mathrm{C}-\mathrm{N}$ species 


\section{WILEY-VCH}

was originated from the decomposition of the $\mathrm{C}_{3} \mathrm{~N}_{4}$ template. ${ }^{[28,30]}$ The $\mathrm{C}$ 1s XPS spectra contained a characteristic peak attributed to graphite at $284.4 \mathrm{eV} \cdot{ }^{[55]}$ The carbide phase for W was confirmed by detecting the characteristic peak at $283.2 \mathrm{eV}$ in the $\mathrm{C} 1 \mathrm{~s}$ spectrum. ${ }^{[56,57]}$

The Ti 2p XPS spectrum of the sample exhibited main doublet lines at $458.4 \mathrm{eV}$ for Ti $2 \mathrm{p}_{3 / 2}$ and $464.1 \mathrm{eV}$ for $\mathrm{Ti} 2 \mathrm{p}_{1 / 2}$, which are characteristic of amorphous $\mathrm{TiO}_{2 .}{ }^{[36,58]}$ The observed shoulder at $454.5 \mathrm{eV}$ for Ti $2 \mathrm{p}_{3 / 2}$ and the binding energy of $\mathrm{N} 1 \mathrm{~s}$ at $396.4 \mathrm{eV}$ both confirm the formation of TiN. ${ }^{[45,46]}$ There is a small peak in the Ti $2 \mathrm{p}$ spectrum at $456.4 \mathrm{eV}$ that is difficult to identify due to the overlap of the signals emitted from the $\mathrm{Ti} 2 \mathrm{p}_{3 / 2}$ of $\mathrm{TiO}_{2}$ and TiN. As a result, this binding energy was attributed to the intermediate phase of Ti-O$\mathrm{N},{ }^{[41]}$ associated with the peak at $395.8 \mathrm{eV}$ in the $\mathrm{N} 1 \mathrm{~s}$ spectrum. ${ }^{[59]}$ The XPS spectrum of the $\mathrm{V} 2 \mathrm{p}$ core level shows the presence of two dominant peaks at binding energies of $517.0 \mathrm{eV}$ for $\mathrm{V} 2 \mathrm{p}_{3 / 2}$ and $524.6 \mathrm{eV}$ for $\mathrm{V} 2 \mathrm{p}_{1 / 2}$, which were assigned to $\mathrm{V}^{5+}$ in $\mathrm{V}_{2} \mathrm{O}_{5}{ }^{[60,61]}$ This surface oxide layer was formed during the passivation step as mentioned previously. ${ }^{[28]}$ Additional doublets were observed at $516.0 \mathrm{eV}$ and $523.6 \mathrm{eV}$ for $\mathrm{V} 2 \mathrm{p}_{3 / 2}$ and $\mathrm{V} 2 \mathrm{p}_{1 / 2}$, respectively, which were close to the reported value of $\mathrm{V} 2 \mathrm{p}$ for the $\mathrm{VO}_{2}$ phase. ${ }^{[62]}$ The XPS spectrum of the core level $\mathrm{Nb} 3 \mathrm{~d}$ shows the presence of three distinct peaks at binding energies of $204.2 \mathrm{eV}, 207.6 \mathrm{eV}$ and $210.4 \mathrm{eV}$. The doublet lines at $207.6 \mathrm{eV}$ for $\mathrm{Nb} 3 \mathrm{~d}_{5 / 2}$ and $210.4 \mathrm{eV}$ for $\mathrm{Nb} 3 \mathrm{~d}_{3 / 2}$ were assigned to $\mathrm{Nb}^{5+}$ in $\mathrm{Nb}_{2} \mathrm{O}_{5}{ }^{[39,63]}$ The peak at $204.2 \mathrm{eV}$ in addition to binding energy at 397.3 $\mathrm{eV}$ for $\mathrm{N} 1 \mathrm{~s}$ both correspond to $\mathrm{NbN}$ phase. ${ }^{[64]} \mathrm{Ta} 4 \mathrm{f}$ showed the presence of two peaks at binding energies of $26.3 \mathrm{eV}$ for $\mathrm{Ta} 4 \mathrm{f}_{7 / 2}$ and $28.2 \mathrm{eV}$ for $\mathrm{Ta} 4 \mathrm{f}_{5 / 2}$, which were assigned to $\mathrm{Ta}^{5+}$ (most likely $\left.\mathrm{Ta}_{2} \mathrm{O}_{5}\right) .{ }^{[48,49]}$ The XPS spectrum of the $\mathrm{Cr} 2 \mathrm{p}$ core level shows a doublet line at 575.6 eV for $\mathrm{Cr} 2 \mathrm{p}_{3 / 2}$ and $585.3 \mathrm{eV}$ for $\mathrm{Cr} 2 \mathrm{p}_{1 / 2}$, which correspond to $\mathrm{Cr}^{3+}$ from $\mathrm{Cr}_{2} \mathrm{O}_{3}{ }^{[51,65]} \mathrm{A}$ shoulder observed at $574.4 \mathrm{eV}$ for $\mathrm{Cr} 2 \mathrm{p}_{3 / 2}$ was assigned to $\mathrm{Cr}^{3+}$ from $\mathrm{CrN}$, together with the characteristic peak at $396.4 \mathrm{eV}$ observed in N 1s. ${ }^{[51,52]}$ The Mo $3 \mathrm{~d}$ core level spectrum showed the presence of three peaks at binding energies of 236.0 and $232.8 \mathrm{eV}$ for Mo $3 \mathrm{~d}_{3 / 2}$ and Mo $3 \mathrm{~d}_{5 / 2}$, respectively, which were assigned to $\mathrm{Mo}^{6+}$ (most likely from $\left.\mathrm{MoO}_{3}\right) .{ }^{[41,66]}$ In addition, 


\section{WILEY-VCH}

$\mathrm{Mo}^{4+}$ (from $\mathrm{MoO}_{2}$ ) was observed at $228.9 \mathrm{eV}^{[67]}$ The XPS spectrum of the $\mathrm{W} 4 \mathrm{f}$ core level shows characteristic peaks at 38.1 and $35.9 \mathrm{eV}$ which were assigned to $\mathrm{W} 4 \mathrm{f}_{7 / 2}$ and $\mathrm{W} 4 \mathrm{f}_{5 / 2}$ doublet for tungsten oxide. ${ }^{[32]}$ A doublet line was detected at binding energy $31.8 \mathrm{eV}$ for $\mathrm{W}$ $4 \mathrm{f}_{7 / 2}$ and $34.0 \mathrm{eV}$ for $\mathrm{W} 4 \mathrm{f}_{5 / 2}$ characteristic for tungsten carbide, consistent with the presence of peak at $283.2 \mathrm{eV}$ in the $\mathrm{C} 1 \mathrm{~s}$ spectrum. ${ }^{[56,57]}$

For $\mathrm{Ti}, \mathrm{V}, \mathrm{Nb}, \mathrm{Ta}$, and $\mathrm{Cr}$ samples, elemental analyses (Table 1) shows comparable or richer amount of nitrogen than that of carbon. For Mo and W, a trace amount of nitrogen is present which indicates that Mo and $\mathrm{W}$ precursors act as a catalyst which almost completely gasified the nitrogen from the template and reacted with carbon fragments to produce carbide phase. The excess amount of carbon unincorporated into the inorganic phase plays an important role to inhibit aggregation of the produced nanoparticles particulay for $\mathrm{Ti}, \mathrm{V}, \mathrm{Nb}$, Ta and Mo as will be confirmed later by TEM. The BET surface areas for the samples (Table 1) were generally higher than $100 \mathrm{~m}^{2} \mathrm{~g}^{-1}$, well reflecting the successful use of $\mathrm{mpg}-\mathrm{C}_{3} \mathrm{~N}_{4}$ template. Note that the contribution of some carbon residue enlarges the surface area. In contrast, low surface area was obtained for $\mathrm{Cr}$ and $\mathrm{W}$ samples because of the nanoparticles aggregation which may due to interparticles interaction attributed to the metallic character of transition metal nitride and carbides. ${ }^{[19,68,69]}$ Also, lack of carbon residue in the case of $\mathrm{W}_{2} \mathrm{C}$ found to be responsible for low surface area of tungsten sample. ${ }^{[70]}$

Fig. 3 shows the TEM images and SAED patterns of the synthesized samples. The TEM images generally show the formation of small $\sim 5 \mathrm{~nm}$ nanocrystals, which reflects the original pore size of the $m p g-\mathrm{C}_{3} \mathrm{~N}_{4}$ template $(6 \mathrm{~nm})$. The particles were dispersed in the matrix of the carbonaceous species, which is consistent with elemental analysis results that confirms the presence of residual carbon. For $\mathrm{Ti}, \mathrm{V}, \mathrm{Nb}$, $\mathrm{Ta}$, and $\mathrm{Cr}$ samples, which are characterized as nitride phase from XRD, the corresponding SAED patterns revealed three diffraction rings whose radii were assigned to the interatomic spacings of the nitride cubic structure crystal planes (111), (200), and (220). The weak rings of spots could be due to the 


\section{WILEY-VCH}

lack of crystallinity or the presence of ultrafine nanoparticles, which is consistent with the XRD pattern. These results were consistent with the XRD pattern, XPS spectra and the high carbon concentrations detected by elemental analysis was formed as a result of the decomposition of carbon nitride template. For Mo and W samples, the corresponding SAED patterns exhibited three diffraction rings whose radii corresponded to the interatomic spacings of hexagonal structure crystal planes (002), (102), and (110).

In this study, we have chosen to investigate the synthesis of various transition metal materials at $1023 \mathrm{~K}$, i.e., the temperature threshold that $m p g-\mathrm{C}_{3} \mathrm{~N}_{4}$ decomposes and reacts. ${ }^{[29,30]}$ Under the similar conditions investigated, identity of metal affects the tendency to form metal nitrides or carbides suggesting that metal reacts with carbon nitride to form metalnitrogen or metal-carbon bonds producing different products and residue, as reported that the decomposition of carbon nitrides is catalytic. ${ }^{[29,30]}$. Similar activity of carbon and nitrogen in the system is expected as the template was identical. As can be considered from Table 2, the tendency to either form carbide or nitride was strongly driven by the free energy of formation, as a consequence of stable crystal structure and electronic configuration. The observed trend indicates that the free energy of formation of nitride is relatively lower for group IV and V transition metals, whereas the carbide phase is relatively more favorable for group VI, in particular for Mo and W. ${ }^{[71,72]}$ This tendency was also found to depend on the electronic structure of the d-band of the transition metals. Carbon and nitrogen donate one and two electrons, respectively, to the d-band of the transition metal, which was split into bonding and antibonding orbitals. Due to the lower d-band filling of group IV transition metals, they tend to accept more electrons. This acceptance is associated with binding to interstitial atoms that provide a high ratio of electrons to the metal. As a result, the most stable group IV nitride phase is formed with a half-filled d-shell. On the other hand, group VI transition metals with higher d-band filling produced carbides rather than nitrides due to an attempt to avoid occupying the antibonding level of the transition metals. ${ }^{[33]}$ 


\section{WILEY-VCH}

\section{Conclusion}

This study synthesized a whole class of group IV-VI metal nitride and carbide nanoparticles by reacting metal precursors with an $m p g-\mathrm{C}_{3} \mathrm{~N}_{4}$ template at $1023 \mathrm{~K}$. The characterization results showed a clear trend in the formation of nitride and carbide phases that primarily depends on the free energy of formation of these compounds. Our study shows that nitrides were produced via the reaction of $\mathrm{Ti}, \mathrm{V}, \mathrm{Nb}$, Ta and $\mathrm{Cr}$ with a reactive carbon nitride template. On the contrary, Mo and $\mathrm{W}$ tend to directly produce carbides rather than nitrides. Our experimental results were found to be in agreement with the thermodynamics of interstitial nitride and carbide formation. The applied synthetic procedure provides control over the size and shape of the produced nanoparticles, which can be achieved by adjusting the size and shape of the original silica used to prepare the reactive template. Thus, this method offers the potential to prepare the desired size, shape and phase of transition metal nitrides and carbides that are suitable for a specific reaction, which is the chief objective of materials chemistry. This paper contributes to the body of knowledge on producing nitride and carbide nanoparticles as non-noble materials for different applications in catalysis and material science.

\section{Acknowledgements}

This work is supported by King Abdullah University of Science and Technology (KAUST). N.S.A. acknowledges Saudi Aramco for financial support.

Received: ((will be filled in by the editorial staff))

Revised: ((will be filled in by the editorial staff)) Published online: ((will be filled in by the editorial staff)) 


\section{WILEY-VCH}

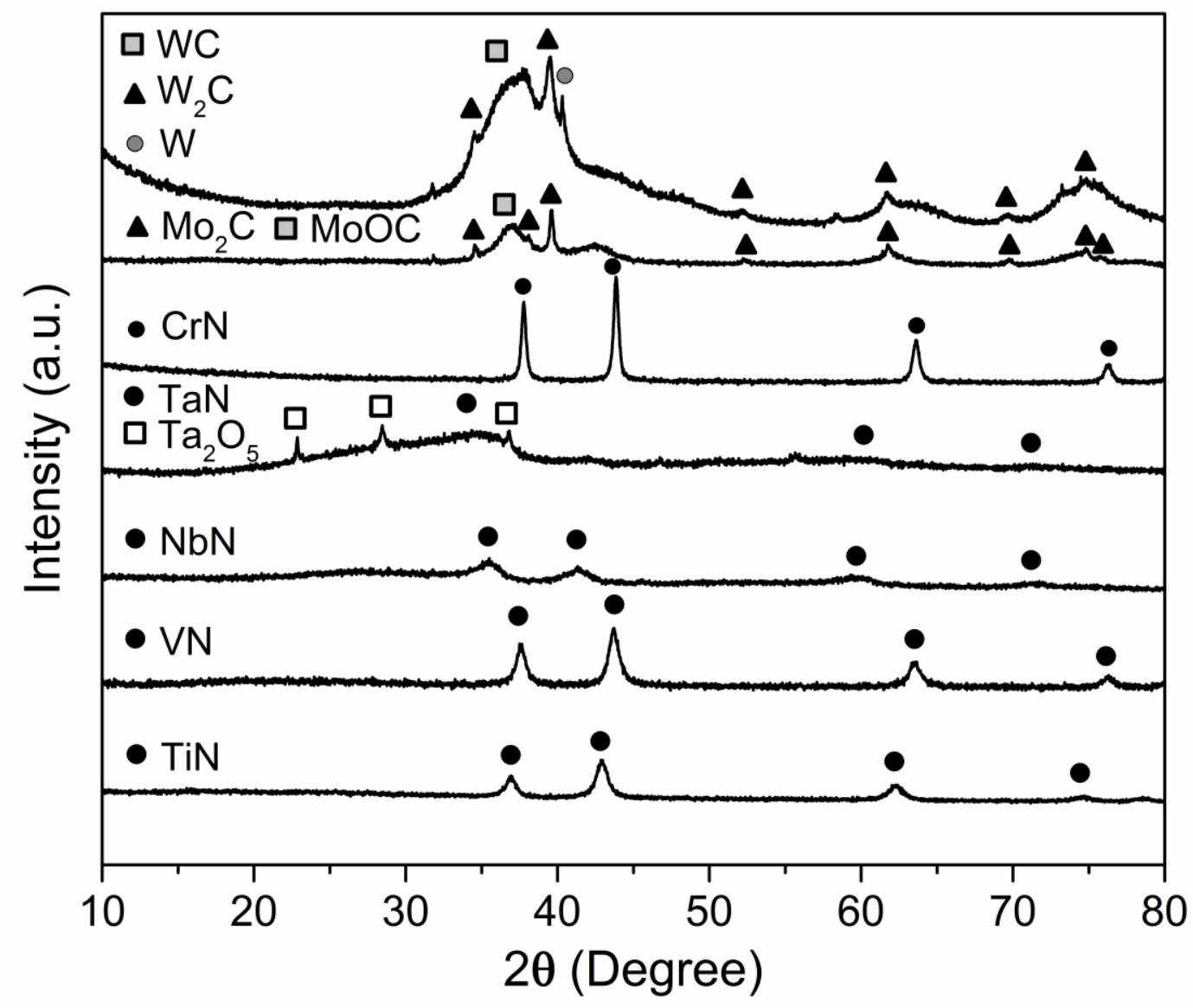

Figure 1. XRD patterns for various samples (Ti, V, Nb, Ta, Cr, Mo, W) synthesized using $\mathrm{mpg}_{-} \mathrm{C}_{3} \mathrm{~N}_{4}$ at $1023 \mathrm{~K}$. 


\section{WILEY-VCH}
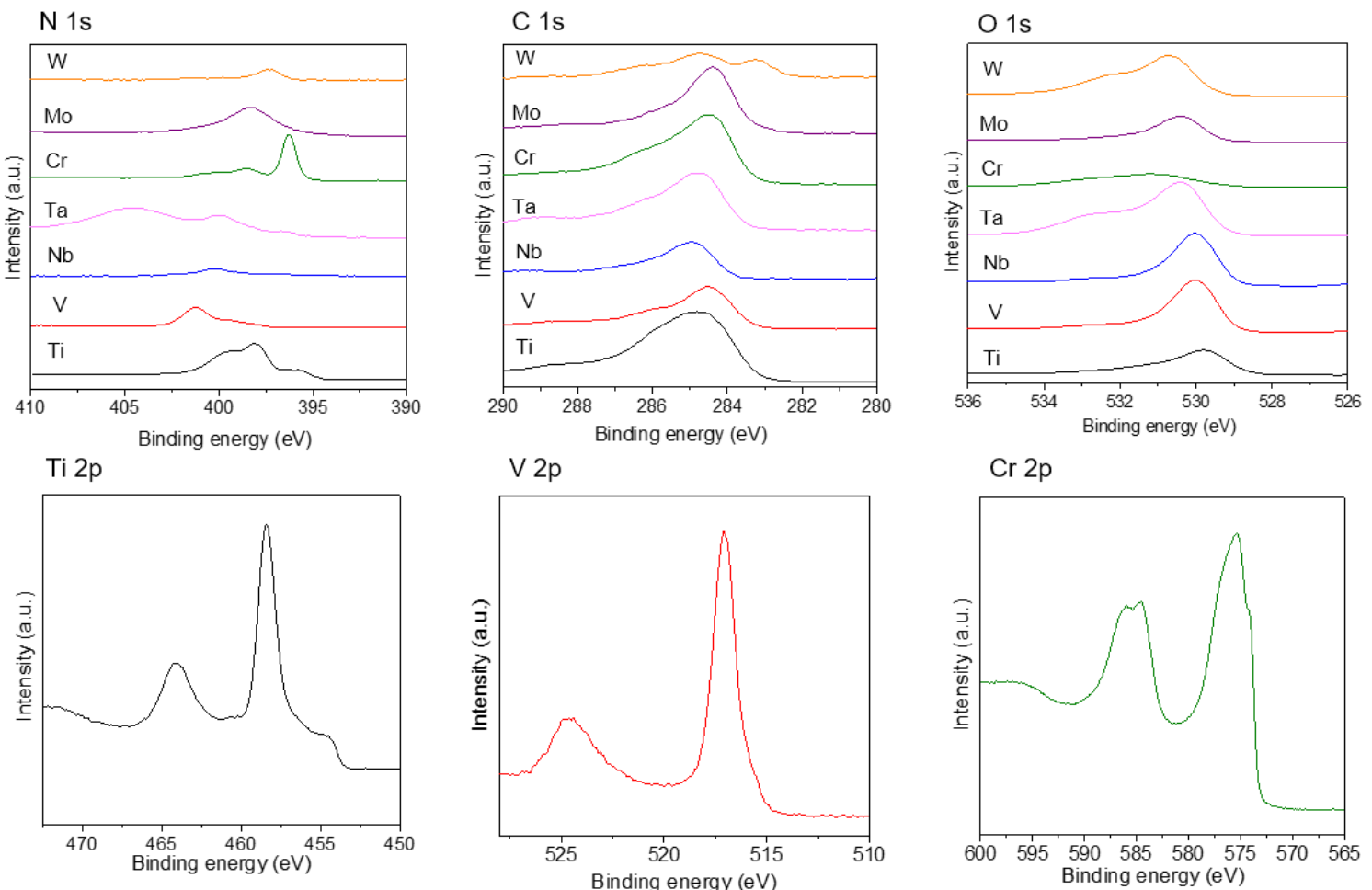

$\mathrm{Nb} 3 \mathrm{~d}$
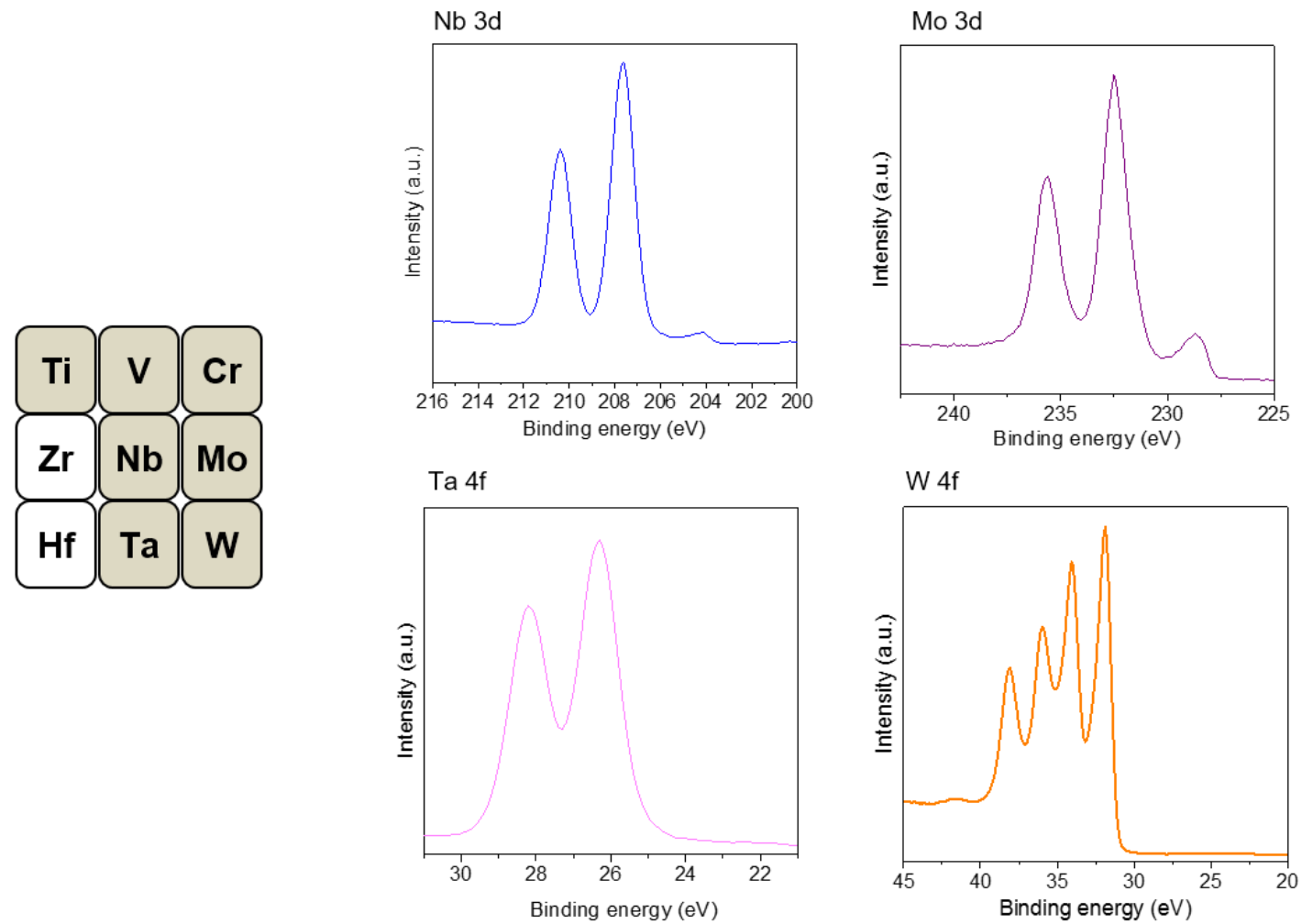

Figure 2. XPS spectra (N 1s, C 1s, O 1s, and electron energies corresponding to various metals) for various samples ( $\mathrm{Ti}, \mathrm{V}, \mathrm{Nb}, \mathrm{Ta}, \mathrm{Cr}, \mathrm{Mo}, \mathrm{W}$ ) synthesized using mpg- $\mathrm{C}_{3} \mathrm{~N}_{4}$ at 1023 $\mathrm{K}$. 


\section{WILEY-VCH}
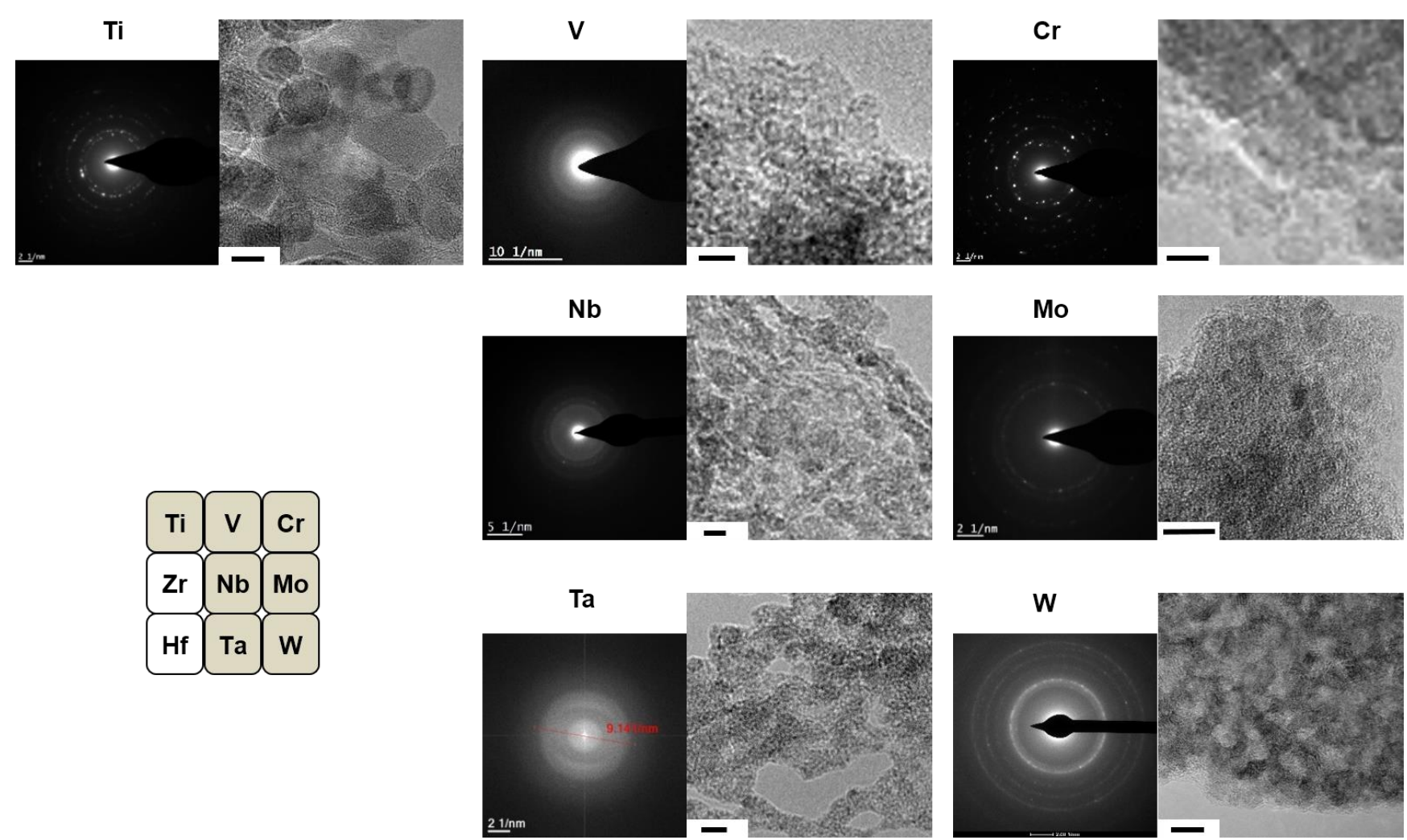

Figure 3. TEM images for various samples ( $\mathrm{Ti}, \mathrm{V}, \mathrm{Nb}, \mathrm{Ta}, \mathrm{Cr}, \mathrm{Mo}, \mathrm{W})$ synthesized using mpg- $\mathrm{C}_{3} \mathrm{~N}_{4}$ at $1023 \mathrm{~K}$. Scale bar: $5 \mathrm{~nm}$.

Table 1. Assignment of XRD patterns, elemental analysis ( $\mathrm{C}$ and $\mathrm{N})$, and BET surface area for various samples.

\begin{tabular}{|c|c|c|c|c|c|c|c|}
\hline $\begin{array}{c}\text { Transition } \\
\text { metals }\end{array}$ & $\begin{array}{c}\text { Atomic } \\
\text { radius }(\mathrm{pm})\end{array}$ & $\begin{array}{l}\text { Ionic radius } \\
(\mathrm{pm})\end{array}$ & $\begin{array}{c}\text { Main } \\
\text { phase }^{a}\end{array}$ & PDF & C (\%) & $\mathrm{N}(\%)$ & $\begin{array}{c}\text { BET } \\
\text { surface } \\
\text { area } \\
\left(\mathrm{m}^{2} \mathrm{~g}^{-1}\right)\end{array}$ \\
\hline $\mathrm{Ti}$ & 146.7 & (III) 81 & $\mathrm{TiN}$ & $01-087-0630$ & 19 & 21 & 146 \\
\hline V & 133.8 & (III) 78 & VN & $00-035-0768$ & 6.0 & 10 & 171 \\
\hline $\mathrm{Nb}$ & 145.6 & (III) 86 & $\mathrm{NbN}$ & 03-065-0436 & 9.3 & 6.8 & 157 \\
\hline $\mathrm{Ta}$ & 145.7 & (III) 86 & $\mathrm{TaN}$ & $03-065-9404$ & 3.7 & 4.8 & 107 \\
\hline $\mathrm{Cr}$ & 126.7 & (III) 76 & $\mathrm{CrN}$ & 00-011-0065 & 8.0 & 12 & 16 \\
\hline Mo & 138.6 & (IV) 79 & $\mathrm{Mo}_{2} \mathrm{C}$ & $00-001-1188$ & 21 & 1.3 & 120 \\
\hline W & 139.4 & (IV) 80 & $\mathrm{~W}_{2} \mathrm{C}$ & 01-079-0743 & 3.5 & 0.3 & 18 \\
\hline
\end{tabular}

a) Assigned from XRD patterns

Table 2. Standard formation energy of various transition metal nitrides and carbides. ${ }^{\text {[71,72] }}$

\begin{tabular}{cccc}
\hline Nitride & $\Delta G_{298}^{\circ}$ & Carbide & $\Delta G_{298}^{\circ}$ \\
\hline $\mathrm{Ti}+1 / 2 \mathrm{~N}_{2} \rightarrow \mathrm{TiN}$ & -309 & $\mathrm{Ti}+\mathrm{C} \rightarrow \mathrm{TiC}$ & -181 \\
$\mathrm{~V}+1 / 2 \mathrm{~N}_{2} \rightarrow \mathrm{VN}$ & -191 & $\mathrm{~V}+\mathrm{C} \rightarrow \mathrm{VC}$ & -99 \\
$\mathrm{Nb}+1 / 2 \mathrm{~N}_{2} \rightarrow \mathrm{NbN}$ & -206 & $\mathrm{Nb}+\mathrm{C} \rightarrow \mathrm{NbC}$ & -136.9 \\
$\mathrm{Ta}+1 / 2 \mathrm{~N}_{2} \rightarrow \mathrm{TiN}$ & -224 & $\mathrm{Ta}+\mathrm{C} \rightarrow \mathrm{TiC}$ & -142.6 \\
$\mathrm{Cr}+1 / 2 \mathrm{~N}_{2} \rightarrow \mathrm{CrN}$ & -92.8 & $\mathrm{Cr}+3 / 2 \mathrm{C} \rightarrow 1 / 3 \mathrm{Cr}_{3} \mathrm{C}_{2}$ & -102.1 \\
$\mathrm{Mo}+1 / 4 \mathrm{~N}_{2} \rightarrow 1 / 2 \mathrm{Mo}_{2} \mathrm{~N}$ & -27.3 & $\mathrm{Mo}+1 / 2 \mathrm{C} \rightarrow \mathrm{Mo}_{2} \mathrm{C}$ & -58.82 \\
$\mathrm{~W}+1 / 4 \mathrm{~N}_{2} \rightarrow 1 / 2 \mathrm{~W}_{2} \mathrm{~N}$ & +39.0 & $\mathrm{~W}+\mathrm{C} \rightarrow \mathrm{WC}$ & -38.48 \\
\hline
\end{tabular}




\section{WILEY-VCH}

\section{References}

[1] C. Giordano, M. Antonietti Nano Today. 2011, 6, 366-380.

[2] J. G. Chen Chem. Rev. 1996, 96, 1477-1498.

[3] D. Ham, J. S. Lee Energies. 2009, 2, 873-899.

[4] J. B. Claridge, A. P. E. York, A. J. Brungs, M. L. H. Green Chem. Mater. 1999, 12, 132142

[5] S. T. Oyama J. Solid State Chem. 1992, 96, 442-445.

[6] S. T. Oyama, G. L. Haller in Catalysis by carbides, nitrides, and Group VIII intermetallic compounds, Vol., The Royal Society of Chemistry, United States, 1982.

[7] S. T. Oyama Catal. Today. 1992, 15, 179-200.

[8] S. Dong, X. Chen, X. Zhang, G. Cui Coord. Chem. Rev. 2013, 257, 1946-1956.

[9] W.-F. Chen, J. T. Muckerman, E. Fujita Chem. Commun. 2013, 49, 8896-8909.

[10] M. K. Neylon, S. Choi, H. Kwon, K. E. Curry, L. T. Thompson Appl. Catal., A. 1999, $183,253-263$.

[11] S. Ramanathan, S. T. Oyama J. Phys. Chem. A. 1995, 99, 16365-16372.

[12] B. Mazumder, A. L. Hector J. Mater. Chem. 2009, 19, 4673-4686.

[13] H. Kumagai, K. Takanabe, J. Kubota, K. Domen, Bull. Chem. Soc. Jpn. 2015, 88, 584590.

[14] A.-M. Alexander, J. S. J. Hargreaves Chem. Soc. Rev. 2010, 39, 4388-4401.

[15] J. Chen, K. Takanabe, R. Ohnishi, D. Lu, S. Okada, H. Hatasawa, H. Morioka, M. Antonietti, J. Kubota, K. Domen Chem. Commun. 2010, 46, 7492-7494.

[16] P. G. Li, M. Lei, Z. B. Sun, L. Z. Cao, Y. F. Guo, X. Guo, W. H. Tang J. Alloys Compd. 2007, 430, 237-240.

[17] W. F. Chen, C. H. Wang, K. Sasaki, N. Marinkovic, W. Xu, J. T. Muckerman, Y. Zhu, R. R. Adzic Energy Environ Sci. 2013, 6, 943-951. 


\section{WILEY-VCH}

[18] C. Giordano, C. Erpen, W. Yao, B. Milke, M. Antonietti Chem. Mater. 2009, 21, 5136-5144.

[19] C. Giordano, C. Erpen, W. Yao, M. Antonietti Nano Lett. 2008, 8, 4659-4663.

[20] W. Yao, P. Makowski, C. Giordano, F. Goettmann Chem. Eur. J. 2009, 15, 1199912004.

[21] A. Fischer, M. Antonietti, A. Thomas Adv. Mater. 2007, 19, 264-267.

[22] Y. Fukasawa, K. Takanabe, A. Shimojima, M. Antonietti, K. Domen, T. Okubo Chem Asian J. 2011, 6, 103-109.

[23] M. Groenewolt, M. Antonietti Adv. Mater. 2005, 17, 1789-1792.

[24] A. Thomas, F. Goettmann, M. Antonietti Chem. Mater. 2008, 20, 738-755.

[25] H. Zhao, M. Lei, X. a. Yang, J. Jian, X. Chen J. Am. Chem. Soc. 2005, 127, 1572215723.

[26] L. Yuliati, J.-H. Yang, X. Wang, K. Maeda, T. Takata, M. Antonietti, K. Domen J. Mater. Chem. 2010, 20, 4295-4298.

[27] A. Fischer, J. O. Müller, M. Antonietti, A. Thomas ACS Nano. 2008, 2, 2489-2496.

[28] N. S. Alhajri, D. H. Anjum, K. Takanabe J. Mater. Chem. 2014, 2, 10548-10556.

[29] A. T. Garcia-Esparza, D. Cha, Y. Ou, J. Kubota, K. Domen, K. Takanabe ChemSusChem. 2013, 6, 168-181.

[30] N. S. Alhajri, H. Yoshida, D. H. Anjum, A. T. Garcia-Esparza, J. Kubota, K. Domen, K. Takanabe J. Mater. Chem. 2013, 1, 12606-12616.

[31] A. Thomas, A. Fischer, F. Goettmann, M. Antonietti, J.-O. Muller, R. Schlogl, J. M. Carlsson J. Mater. Chem. 2008, 18, 4893-4908.

[32] R. Ohnishi, K. Takanabe, M. Katayama, J. Kubota, K. Domen J. Phys. Chem. C. 2012, $117,496-502$.

[33] H. O. Pierson, Handbook of Refractory Carbides and Nitrides, William Andrew Publishing, Norwich, United States, 1996. 


\section{WILEY-VCH}

[34] L. E. Toth, Transition Metal Carbides and Nitrides, Academic Press, New YorkLondon, 1971.

[35] Y. Liu, T. G. Kelly, J. G. Chen, W. E. Mustain ACS Catal. 2013, 3, 1184-1194.

[36] N. C. Saha, H. G. Tompkins J. Appl. Phys. 1992, 72, 3072-3079.

[37] B. Avasarala, P. Haldar Electrochim. Acta. 2010, 55, 9024-9034.

[38] M. Detroye, F. Reniers, C. Buess-Herman, J. Vereecken Appl. Surf. Sci. 1999, 144$145,78-82$.

[39] N. Özer, M. D. Rubin, C. M. Lampert Sol. Energy Mater. Sol. Cells. 1996, 40, 285296.

[40] M. Hassel, I. Hemmerich, H. Kuhlenbeck, H.-J. Freund Surf. Sci. Spectra. 1996, 4, 246-252.

[41] W. Lisowski, A. H. J. Van Den Berg, L. J. Hanekamp, A. Van Silfhout Surf. Interface Anal. 1992, 19, 93-99.

[42] O. Y. Khyzhun J. Alloys Compd. 2000, 305, 1-6.

[43] F. P. J. M. Kerkhof, J. A. Moulijn, A. Heeres J. Electron. Spectrosc. Relat. Phenom. 1978, 14, 453-466.

[44] F. Y. Xie, L. Gong, X. Liu, Y. T. Tao, W. H. Zhang, S. H. Chen, H. Meng, J. Chen J. Electron. Spectrosc. Relat. Phenom. 2012, 185, 112-118.

[45] M. J. Vasile, A. B. Emerson, F. A. Baiocchi J Vac Sci Technol A. 1990, 8, 99-105.

[46] H. Irie, Y. Watanabe, K. Hashimoto J. Phys. Chem. B. 2003, 107, 5483-5486.

[47] A. C. Newport, J. E. Bleau, C. J. Carmalt, I. P. Parkin, S. A. O'Neill J. Mater. Chem. 2004, 14, 3333-3336.

[48] J. K. Schaeffer, C. Capasso, R. Gregory, D. Gilmer, L. R. C. Fonseca, M. Raymond, C. Happ, M. Kottke, S. B. Samavedam, P. J. Tobin, B. E. White J. Appl. Phys. 2007, 101, -. [49] L. I. Johansson Surf. Sci. Rep. 1995, 21, 177-250. 


\section{WILEY-VCH}

[50] O. J. Bchir, K. C. Kim, T. J. Anderson, V. Craciun, B. C. Brooks, L. McElwee-White J. Electrochem. Soc. 2004, 151, G697-G703.

[51] T. Jiang, I. Odnevall Wallinder, G. Herting isrn corros. 2012, 2012, 10.

[52] A. Conde, A. B. Cristóbal, G. Fuentes, T. Tate, J. de Damborenea Surf. Coat. Technol. 2006, 201, 3588-3595.

[53] S. E. M. Rodil, N. A. ; Robertson, J. ; Milne, W. I. Phys. Status Solidi A. 1999, 174, 25-37.

[54] V. N. Khabashesku, J. L. Zimmerman, J. L. Margrave Chem. Mater. 2000, 12, 32643270.

[55] W. Chen, H. Xu, L. Liu, X. Gao, D. Qi, G. Peng, S. C. Tan, Y. Feng, K. P. Loh, A. T. S. Wee Surf. Sci. 2005, 596, 176-186.

[56] R. Ganesan, J. S. Lee Angew. Chem. 2005, 117, 6715-6718.

[57] P. V. Krasovskii, O. S. Malinovskaya, A. V. Samokhin, Y. V. Blagoveshchenskiy, V. A. Kazakov, A. A. Ashmarin Appl. Surf. Sci. 2015, 339, 46-54.

[58] F.-H. Lu, H.-Y. Chen Thin Solid Films. 1999, 355-356, 374-379.

[59] M. Drygaś, C. Czosnek, R. T. Paine, J. F. Janik Chem. Mater. 2006, 18, 3122-3129.

[60] E. Hryha, E. Rutqvist, L. Nyborg Surf. Interface Anal. 2012, 44, 1022-1025.

[61] J.-G. Choi Appl. Surf. Sci. 1999, 148, 64-72.

[62] A. Romanyuk, R. Steiner, L. Marot, V. Spassov, P. Oelhafen Thin Solid Films. 2008, $516,8513-8516$.

[63] G. Jouve, C. Séverac, S. Cantacuzène Thin Solid Films. 1996, 287, 146-153.

[64] I. Brown J Vac. Sci. Technol. A. 2001, 19, 2048-2050.

[65] G. C. Allen, M. T. Curtis, A. J. Hooper, P. M. Tucker J. Chem. Soc., Dalton Trans. 1973, $1675-1683$.

[66] C. Díaz, V. Lavayen, C. O'Dwyer J. Solid State Chem. 2010, 183, 1595-1603.

[67] F. Werfel, E. Minni J. Phys. C: Solid State Phys. 1983, 16, 6091-6100. 


\section{WILEY-VCH}

[68] Y. Li, L. Gao, J. Li, D. Yan J. Am. Ceram. Soc. 2002, 85, 1294-1296.

[69] H. Zhong, X. Chen, H. Zhang, M. Wang, S. S. Mao Appl. Phys. Lett. 2007, 91, 163103.

[70] R. Ohnishi, M. Katayama, D. Cha, K. Takanabe, J. Kubota, K. Domen J. Electrochem. Soc. 2013, 160, F501-F506.

[71] H. A. Wriedt Bull Alloy Phase Diagr. 1989, 10, 358-367.

[72] J. Lohmar, H. Rickert J. Chem. Thermodyn. 1978, 10, 1209.

Keyword: transition metal carbide, transition metal nitride, nanoparticles, carbon nitride

\section{ToC}

\section{A series of transition metal (Group IV-VI) nitrides and carbides nanoparticles are}

synthesized using reactive mpg- $\mathrm{C}_{3} \mathrm{~N}_{4}$ template. $m p g-\mathrm{C}_{3} \mathrm{~N}_{4}$ not only provides confined spaces for restricting primary particle size but also acts as a chemical source of nitrogen and carbon. Thermodynamically-driven formation results in two distinctive trend of nitride or carbide, where $\mathrm{Ti}, \mathrm{V}, \mathrm{Nb}$, Ta, and $\mathrm{Cr}$ forms nitride while Mo and $\mathrm{W}$ forms carbide at $1023 \mathrm{~K}$.

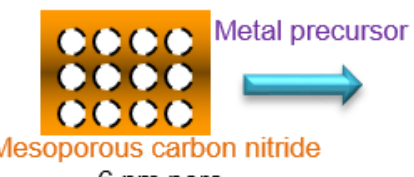

$\sim 6 \mathrm{~nm}$ pore

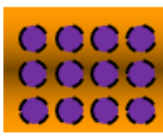

$\mathrm{COCO}$
Heat treatment

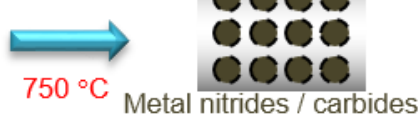

$<10 \mathrm{~nm}$ 